\title{
BMJ Open Obesity in pregnancy: a retrospective prevalence-based study on health service utilisation and costs on the NHS
}

\author{
Kelly L Morgan, ${ }^{1}$ Muhammad A Rahman, ${ }^{1}$ Steven Macey, ${ }^{2}$ Mark D Atkinson, ${ }^{1}$ \\ Rebecca A Hill, ${ }^{1}$ Ashrafunnesa Khanom, ${ }^{1}$ Shantini Paranjothy, ${ }^{3}$ \\ Muhammad Jami Husain, ${ }^{4}$ Sinead T Brophy ${ }^{1}$
}

To cite: Morgan KL, Rahman MA, Macey S, et al. Obesity in pregnancy: a retrospective prevalencebased study on health service utilisation and costs on the NHS. BMJ Open 2014;4: e003983. doi:10.1136/ bmjopen-2013-003983

- Prepublication history and additional material for this paper is available online. To view these files please visit the journal online (http://dx.doi.org/10.1136/ bmjopen-2013-003983)

Received 9 September 2013 Revised 10 January 2014 Accepted 21 January 2014

CrossMark

For numbered affiliations see end of article.

Correspondence to

Kelly Morgan;

kelly.morgan@swansea.ac.uk

\section{ABSTRACT}

Objective: To estimate the direct healthcare cost of being overweight or obese throughout pregnancy to the National Health Service in Wales.

Design: Retrospective prevalence-based study. Setting: Combined linked anonymised electronic datasets gathered on a cohort of women enrolled on the Growing Up in Wales: Environments for Healthy Living (EHL) study. Women were categorised into two groups: normal body mass index (BMI; $n=260$ ) and overweight/obese (BMl>25; $n=224)$.

Participants: 484 singleton pregnancies with available health service records and an antenatal BMI.

Primary outcome measure: Total health service utilisation (comprising all general practitioner visits and prescribed medications, inpatient admissions and outpatient visits) and direct healthcare costs for providing these services in the year 2011-2012. Costs are calculated as cost of mother (no infant costs are included) and are related to health service usage throughout pregnancy and 2 months following delivery.

Results: There was a strong association between healthcare usage cost and BMI $(p<0.001)$. Adjusting for maternal age, parity, ethnicity and comorbidity, mean total costs were $23 \%$ higher among overweight women (rate ratios (RR) $1.23,95 \% \mathrm{Cl} 1.230$ to 1.233 ) and $37 \%$ higher among obese women (RR 1.39, 95\% $\mathrm{Cl} 1.38$ to 1.39) compared with women with normal weight. Adjusting for smoking, consumption of alcohol, or the presence of any comorbidities did not materially affect the results. The total mean cost estimates were $£ 3546.3$ for normal weight, $£ 4244.4$ for overweight and $£ 4717.64$ for obese women.

Conclusions: Increased health service usage and healthcare costs during pregnancy are associated with increasing maternal BMI; this was apparent across all health services considered within this study.

Interventions costing less than £1171.34 per person could be cost-effective if they reduce healthcare usage among obese pregnant women to levels equivalent to that of normal weight women.

\section{BACKGROUND}

Maternal obesity is a growing health concern throughout the UK with approximately 1 in

\section{Strengths and limitations of this study}

- The ability to control for potential confounders and comorbidities at the patient level, and the use of medically recorded early-pregnancy body mass index (BMI).

- This study provides evidence that overweight and obese women have greater healthcare usage and accompanying costs throughout pregnancy when compared to normal weight women.

- Limitations include the use of a BMI value recorded at a single time point, challenges presented when quantifying health service utilisation and the disregard of indirect and intangible health service costs.

20 women being obese during pregnancy. Varying considerably across nations, rates of maternal obesity range from 1 in 15 women living in Wales to lower proportions of 1 in 29 women in London. ${ }^{1}$ Associated with increasing problems throughout pregnancy, ${ }^{2}$ delivery complications ${ }^{3-5}$ and poor neonatal outcomes, ${ }^{6} 7$ maternal obesity is currently one of the biggest challenges presented to maternity services in the UK. ${ }^{1}$ In a qualitative study in the UK, health professionals noted that obese expectant mothers and offspring required significantly higher levels of care. ${ }^{8}$ Accompanying increasing health service utilisation, cost repercussions are also eminent among the obese population. Cost-of-illness studies provide a tool for quantifying this economic burden and estimate the total cost savings which would ensue if obesity was absent. $^{9}$

Previous studies have shown a $2.3 \%$ increase in total direct healthcare costs for every unit increase in body mass index (BMI) among non-pregnant women, with more hospitalisations, higher rates of prescription drugs and greater outpatient visits 
in obese women. ${ }^{10}$ An earlier study investigating healthcare costs relating to obesity at a patient level reported higher rates of inpatient days, higher number and costs of outpatient visits, laboratory usage and overall total costs, with mean annual costs $25 \%$ higher in obese individuals (BMI greater than or equal to $30 \mathrm{~kg} / \mathrm{m}^{2}$ ) compared with those with a normal BMI (BMI 20-24.9 kg/ $\left.\mathrm{m}^{2}\right) .{ }^{11}$ A recent systematic review focusing on the healthcare costs of obesity worldwide included 32 selected studies of which 1 was based in the UK. ${ }^{12}$ Studies were based on either modelling or database analyses and, despite varying methodologies, all 32 studies were in agreement that obesity placed a financial strain on health economics with direct healthcare costs ranging between $0.7 \%$ and $2.8 \%$ of a country's total healthcare expenditure. Limitations apparent across many of the studies included use of self-reported BMI, varying BMI cut-offs for defining obesity, and population attributable risk designs. The UK-based study was deemed as having the lowest methodological quality due to its crosssectional design and use of aggregate level data. ${ }^{13}$ Thus, there is a need for higher quality UK-based studies, as highlighted by the Centre for Maternal and Child Enquiries (CMACE) report. ${ }^{1}$

To date, research focusing on healthcare costs accrued by obese expectant mothers in comparison with nonobese counterparts is limited. Previous research within this area has focused on prenatal care attendance among low-income working women,${ }^{14}$ cost of high-risk pregnancies receiving in-home nursing care ${ }^{15}$ and costs associated with complicated pregnancies. ${ }^{16} \mathrm{~A}$ recent study compared healthcare costs (including those related to neonatal care) between women with and without gestational diabetes mellitus (GDM), of whom all had a BMI greater than or equal to $25 \mathrm{~kg} / \mathrm{m}^{2}{ }^{17}$ Adjusting for age, education and BMI, the authors reported greater inpatient costs (44\% higher) among those women with GDM. Based on participants from a Finnish prevention trial, the authors emphasise that they cannot rule out any potential intervention effects on healthcare use.

Despite being scarce, research to date has shown the increasing demands of excess weight on health service utilisation and resultant economic implications. The current challenging economic climate calls for careful management of healthcare funds. ${ }^{18}$ Interventions are therefore needed to examine the effect of reducing healthcare use among women presenting with a BMI above normal. Previously described as a 'powerful motivator', pregnancy could represent the optimal time for the adoption of positive lifestyle choices and ultimately impact maternal and offspring health and well-being. ${ }^{19}$ Accurately identifying the cost of healthcare usage by overweight and obese women during pregnancy will enable future interventions to efficiently devise costeffective methods targeting maternal obesity while reducing associated National Health Service (NHS) costs. No UK-based study to date has comprehensively analysed the costs to the NHS associated with overweight and obesity during pregnancy. The aim of this paper is to investigate health service utilisation and accompanying costs among normal weight and overweight/obese pregnant women. Direct healthcare costs associated with general practitioner (GP) visits and prescriptions, inpatient admissions and outpatient visits shall be calculated to provide a descriptive account of healthcare use. Our hypothesis is that overweight/obese women have higher health service utilisation and accompanying costs during pregnancy in comparison with normal weight women. This difference in cost could be used to inform the amount that could be spent on public health initiatives and still be cost saving.

\section{RESEARCH METHODS AND DESIGN}

\section{Study sample}

We conducted a retrospective prevalence-based study of pregnant women who took part in the 'Growing Up in Wales: Environments for Healthy Living'(EHL) birth cohort study. ${ }^{20}$ All pregnant women aged 16 and older receiving antenatal care (during the period 2010-2013) through the Abertawe Bro Morgannwg University (ABMU) NHS Board were eligible to participate in the cohort. Providing health services for a population of 500000 individuals, ABMU NHS Board is the largest health board in Wales comprising of 18 hospitals and 77 GP clinics. A more in-depth description of the study population has previously been described elsewhere. ${ }^{20}$ Briefly, each participant completed a questionnaire during pregnancy providing information on age, ethnicity, education level, socioeconomic status, cigarette smoking and alcohol consumption. Table 1 outlines all study variables and the source from which they were obtained.

Exclusion criteria for the present study were nonsingleton pregnancies, incomplete pregnancies, mothers without a recorded BMI in the antenatal records, mothers with pre-existing diabetes, mothers with cancer and mothers not registered with a GP for longer than a year preceding the study period.

\section{BMI categories}

Participant BMI was calculated by a mid-wife during the antenatal booking appointment (around 12 weeks gestation) and recorded in the antenatal notes. For the purposes of this study, women were categorised into two BMI groups: normal BMI (BMI 18.5-24.9 $\mathrm{kg} / \mathrm{m}^{2} ; \mathrm{n}=260$ ) and overweight/obese BMI (BMI $\left.\geq 25 \mathrm{~kg} / \mathrm{m}^{2} ; \mathrm{n}=224\right)$.

\section{Health services use data}

Using the Secure Anonymised Information Linkage (SAIL) databank developed at Swansea University, ${ }^{21}$ routinely collected electronic medical records were used to establish health service utilisation throughout the course of pregnancy and 2 months postdelivery. Data concerning health service use (ie, diagnoses, medications, 


\begin{tabular}{|c|c|c|}
\hline Variable & Source & Levels \\
\hline Age at delivery & $\begin{array}{l}\text { Antenatal maternity } \\
\text { notes }\end{array}$ & 18-44, mean 29.5 \\
\hline Ethnicity & Study questionnaire & $\begin{array}{l}\text { Caucasian/European ( } 91.1 \%) \text {, African/Caribbean (1.1\%), Asian } \\
(3.9 \%) \text { or other }(3.9 \%)\end{array}$ \\
\hline Smoking status & Study questionnaire & Yes $(18.8 \%)$ or no $(81.2 \%)$ \\
\hline Alcohol consumption & Study questionnaire & Yes $(38.9 \%)$ or no $(61.1 \%)$ \\
\hline Employment & Study questionnaire & $\begin{array}{l}\text { Full-time }(42.3 \%) \text {, part-time }(24.5 \%) \text {, unemployed }(11.5 \%) \text {, } \\
\text { homemaker }(15 \%) \text {, student }(2.5 \%) \text {, self-employed }(2.2 \%) \\
\text { and other }(2 \%)\end{array}$ \\
\hline Annual household income & Study questionnaire & $\begin{array}{l}£ 0-£ 9999(10.4 \%), £ 10000-£ 14999(10.4 \%), £ 15000-£ 24999 \\
(15.9 \%), £ 25000-£ 34999(12.9 \%), £ 35000-£ 39999(9.2 \%), \\
£ 40000-£ 49999(15.1 \%), £ 50000-£ 99999(18.4 \%), £ 100000+ \\
(2 \%) \text { and do not know (5.7\%) }\end{array}$ \\
\hline Parity & Study questionnaire & $0-4$, mean 0.8 \\
\hline Early pregnancy BMI & $\begin{array}{l}\text { Antenatal maternity } \\
\text { notes }\end{array}$ & Overweight/obese (BMl>25 kg/m², 46.2\%), or normal $(53.8 \%)$ \\
\hline $\begin{array}{l}\text { Non-specific psychological } \\
\text { distress }\end{array}$ & Study questionnaire & 0-24, mean 4.2 (Kessler 6 scale) \\
\hline $\begin{array}{l}\text { Comorbidities (within } 3 \text { years } \\
\text { prior to conception) }\end{array}$ & Primary care dataset & Charlson index (see online supplementary table S1) \\
\hline
\end{tabular}

investigations and results) are coded within the databank using Read codes, the standard terminology system used in the UK. ${ }^{22}$ Only Read codes relating to the healthcare of the mother were included. The Primary Care dataset within SAIL provided the total number of visits to a GP for each participant over the defined time period and all records of any prescribed medications. The methodology adopted to calculate the total number of visits to a GP was to: (1) count a record as a visit to the GP if two Read codes were present on the same day, (2) count only one visit per day (ie, if there was more than one record of an event on the same day, only one GP visit was counted) and (3) exclude all Read codes relating to medications (indicated by GP Read codes starting with small letters $a-z$ ). The Patient Episode Database for Wales (PEDW) was searched for inpatient admissions, inpatient durations and outpatient visits. For each visit record a distinct event was used, for example, if more than one outpatient record was recorded on the same date, only one event was used in the analyses.

\section{Economic analysis}

This study adopted an econometric approach in order to compare the mean differences in healthcare costs accrued in two groups based on BMI; normal $\left(\mathrm{BMI}<24.9 \mathrm{~kg} / \mathrm{m}^{2}\right)$ and overweight/obese (BMI $\geq 25 \mathrm{~kg}$ / $\mathrm{m}^{2}$ ). All health service costs are only NHS-related and concern health service utilisation associated with only the mother. Costs concerning inpatient and outpatient utilisation are extracted from the Welsh Costing Return (WCR) 2011-2012 in which costings are fully inclusive of any treatments, medications and operations, which may occur during a patient event and are aggregated by specialty type. ${ }^{23}$ Unit Costs of Health and Social Care 2011 provided a unit cost for each GP visit. ${ }^{24}$ For the purpose of this study, applied unit costs were based on a clinic consultation lasting $17.2 \mathrm{~min}$ (including direct care staff costs and qualifications). Costs of prescription drugs were determined by the British National Formulary November $2011^{25}$ applying specific costs for each medication Read code. Costs were not included in cases where medications referred to the treatment of infants, and Read codes not specifying medication dose were assigned the lowest unit price.

\section{Comorbidities}

As obesity is often associated with a number of health problems, the presence of comorbidities in the Primary Care dataset were identified using the Charlson Index. ${ }^{26}$ A complete list of all comorbidities and accompanying Read V.2 codes ( provided by Khan $e t a l^{27}$ ) are located in online supplementary table S1. A time scale of 3 years prior to the date of conception was used to identify comorbidities.

\section{Statistical analyses}

Descriptive characteristics for normal weight and overweight/obese women were tabulated alongside outcomes and covariates. Outcomes which were verified by a counting process (ie, number of GP visits, number of inpatient admissions, number of inpatient days and number of outpatient visits) were analysed using a Poisson regression approach. Differences between healthcare cost and BMI category were analysed using log linear models providing estimates of rate ratios (RR), where the specifications included various control variables, that is, age, ethnicity, 
parity and other confounders. STATA V.12.1 (STATA, Texas, USA) was used for all statistical analyses and statistical significance was set at $\mathrm{p}<0.05$ throughout. As women with existing comorbidities may require greater need for surveillance during pregnancy, outcomes were adjusted according to the presence of one or more conditions.

\section{RESULTS}

\section{Demographics}

Of the total cohort population, $484(66.9 \%)$ women met the inclusion criteria and were included within this study. Ninety-one per cent of the population were of white ethnicity with an even spread of women above and below age 30 years observed. Figure 1 highlights the process for obtaining the study population, and descriptive statistics for both groups of women are shown in table 2. Forty-six per cent of women comprised the overweight group, of whom $11 \%$ were obese (BMI $\geq 30 \mathrm{~kg}$ / $\left.\mathrm{m}^{2}\right)$. Across both groups, proportions of all four ethnic categories and maternal age were similar. Proportions of unemployed women were almost identical in the two groups ( $11.4 \%$ of normal vs $11.5 \%$ of overweight group) whereas the overweight group showed a higher proportion of women undertaking part-time/seasonal work $(30.1 \%$ vs $19.7 \%, \mathrm{p}<0.02)$. Overweight women were also more likely to have two or more children in comparison with the normal weight group $(p=0.05)$. No significant differences were observed between the number of women smoking, consuming alcohol, having an existing comorbidity or non-specific psychological distress between the two groups.

\section{Health service utilisation}

Following adjustment for confounding factors (age, ethnicity and parity), the usage rate of all healthcare services was higher for women in the overweight group compared with the normal weight group (table 3). Specifically, the overweight group experienced an $18 \%$ higher rate of inpatient visits and a 36\% higher rate of inpatient duration. Examining GP data, a 17\% higher visit rate and $14 \%$ higher prescription of medications were shown. Examining the type of inpatient specialties accessed revealed no significant differences between groups. The majority of visits for both groups were shown across maternity services $(93.7 \%$ for normal BMI vs $90.2 \%$ for overweight and obese) while the overweight-obese group presented higher numbers of medical specialty visits $(6.3 \%$ vs $3.7 \%)$. Further adjusting for smoking and alcohol consumption did not result in a noticeable change to the adjusted (age, ethnicity and parity) findings.

\section{Cost evaluation}

There was a strong association between mean total costs and BMI, with the overweight group costing on average $22 \%$ higher for all total mean costs $(\mathrm{p}<0.01)$. Table 4 provides a breakdown of mean costs for each health service, revealing that all mean total costs were greater among those women with a BMI of 25 or more.

We conducted a subset analysis obtaining adjusted (age, ethnicity and parity) estimates for total healthcare costs of overweight $(n=157)$ and obese $(n=67,10.4 \%$ had a BMI exceeding $40 \mathrm{~kg} / \mathrm{m}^{2}$ ) women (table 5 , model 1 ). In comparison with participants with a normal BMI,
Figure 1 Flow diagram displaying participant involvement throughout study selection (BMI, body mass index).

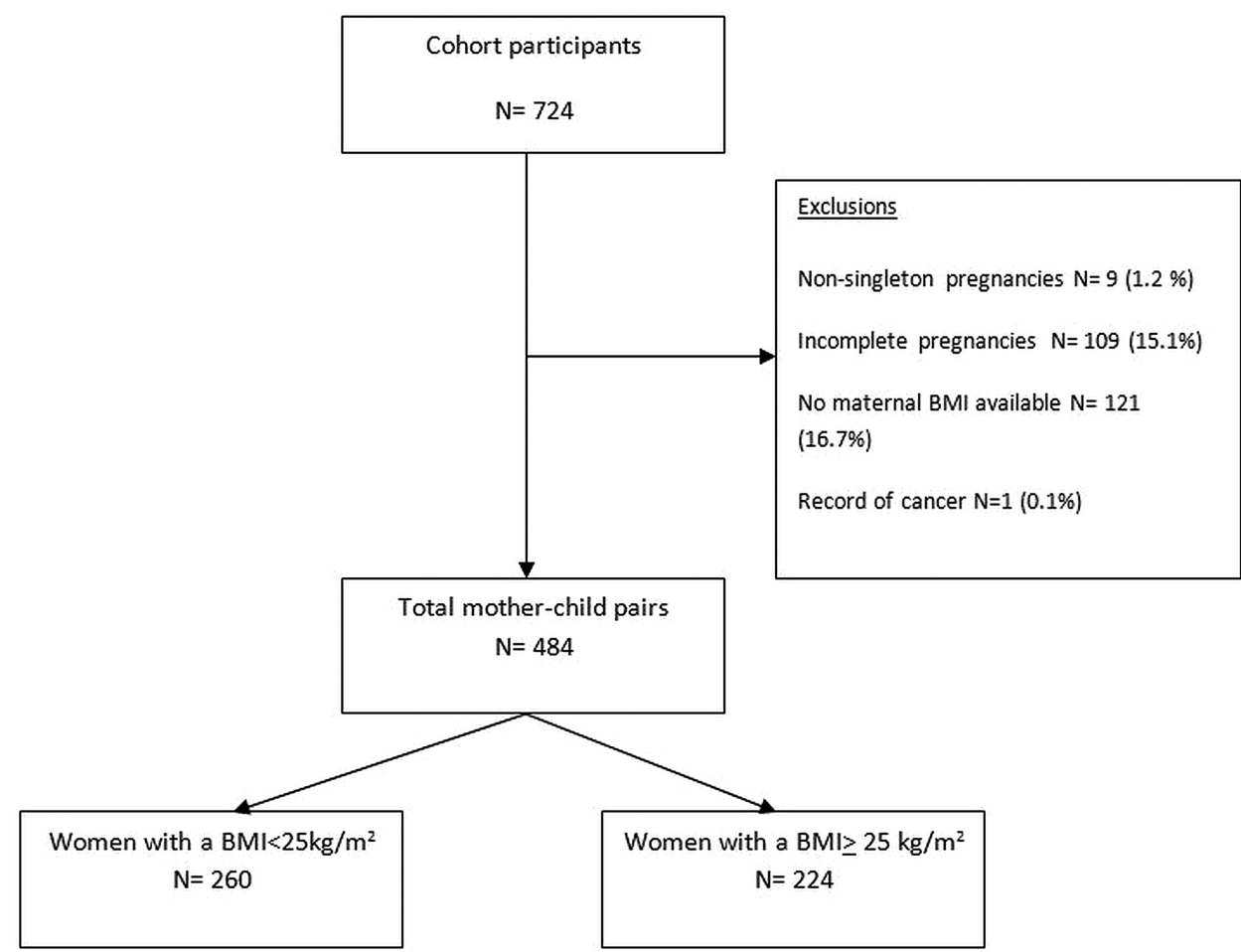


Table 2 Characteristics of study participants by BMI (presented as number (\%))

\begin{tabular}{|c|c|c|}
\hline Characteristics (n) & $\begin{array}{l}\text { Normal BMI } \\
\text { BMI 18.5- } \\
24.9 \\
(\mathrm{~N}=260)\end{array}$ & $\begin{array}{l}\text { Overweight } \\
\text { plus } \\
\text { BMl>24.9 } \\
(\mathrm{N}=224)\end{array}$ \\
\hline \multicolumn{3}{|l|}{ Age at delivery (year; $n=481$ ) } \\
\hline $18-19$ & $8(3.1)$ & $8(3.6)$ \\
\hline $20-25$ & $51(19.8)$ & $37(16.6)$ \\
\hline $26-30$ & $70(27.1)$ & $66(29.6)$ \\
\hline $31-35$ & $66(25.6)$ & $49(22)$ \\
\hline $36-40$ & $56(21.7)$ & $54(24.2)$ \\
\hline$\geq 40$ & $7(2.7)$ & $9(4)$ \\
\hline \multicolumn{3}{|l|}{ Ethnic group $(n=448)$} \\
\hline Caucasian/European & $223(91.4)$ & $185(90.7)$ \\
\hline African/Caribbean & $1(0.4)$ & $4(2)$ \\
\hline Asian & $10(4.1)$ & $8(4)$ \\
\hline Other & $10(4.1)$ & $7(3.4)$ \\
\hline \multicolumn{3}{|l|}{ Annual income $(n=400)$} \\
\hline$£ 0-£ 9999$ & $18(8.6)$ & $24(12.5)$ \\
\hline$£ 10000-£ 14999$ & $20(9.5)$ & $22(11.4$ \\
\hline$£ 15000-£ 24999$ & $32(15.2)$ & $32(16.6)$ \\
\hline$£ 25000-£ 34999$ & $30(14.3)$ & $22(11.4)$ \\
\hline$£ 35000-£ 39999$ & $20(9.5)$ & $16(8.8)$ \\
\hline$£ 40000-£ 49999$ & $29(13.8)$ & $32(16.6)$ \\
\hline$£ 50000-£ 99999$ & $45(21.4)$ & $29(15)$ \\
\hline$£ 100000+$ & $6(2.9)$ & $2(1)$ \\
\hline Do not know & $10(4.8)$ & $13(6.7)$ \\
\hline \multicolumn{3}{|l|}{ Working status $(n=454)$} \\
\hline Full-time & $115(46.8)$ & 78 (37.3) \\
\hline Part-time or casual & 48 (19.7) & $63(30.1)$ \\
\hline Unemployed & $28(11.4)$ & $24(11.5)$ \\
\hline Homemaker & $36(14.6)$ & 32 (15.3) \\
\hline Student & $9(3.7)$ & $3(1.5)$ \\
\hline Self-employed & $6(2.4)$ & $4(1.9)$ \\
\hline Other & $4(1.6)$ & $5(2.4)$ \\
\hline \multicolumn{3}{|l|}{ Parity $(n=484)$} \\
\hline 0 & $141(54.2)$ & $81(36.2)$ \\
\hline 1 & 82 (31.5) & 96 (42.9) \\
\hline 2 & $24(9.2)$ & 29 (12.9) \\
\hline$\geq 3$ & $13(5.1)$ & $18(8)$ \\
\hline $\begin{array}{l}\text { Comorbidity within } 3 \text { years } \\
\text { prior }(n=484)\end{array}$ & $18(6.3)$ & $17(7.6)$ \\
\hline Smoker $(n=409)$ & $49(20.2)$ & $35(17.1)$ \\
\hline $\begin{array}{l}\text { Alcohol consumption } \\
(\mathrm{n}=411)\end{array}$ & 89 (36.3) & $86(41.7)$ \\
\hline $\begin{array}{l}\text { Non-specific psychological } \\
\text { distress score }{ }^{*} \geq 12(n=449)\end{array}$ & $20(51.3)$ & $19(48.7)$ \\
\hline
\end{tabular}

overweight and obese women experienced $23 \%$ and $37 \%$ higher total healthcare costs, respectively (overweight RR $1.23,95 \%$ CI 1.22 to 1.23 , obese RR $1.37,95 \%$ CI 1.38 to 1.39). To assess the impact of existing comorbidities on the variation of health service costs and BMI, we further included comorbidities as an independent variable alongside age, ethnicity and parity (table 5, model 2). The results showed that the RR remained constant for overweight women while the RR of the obese group increased by $2 \%$.
Table 3 Adjusted rate ratios of healthcare usage

\begin{tabular}{lll}
\hline Risk factor & Incidence RR & 95\% $\mathbf{~ I ~}$ \\
\hline Inpatient visits adjusted for & \\
Overweight & 1.18 & 1.1 to 1.3 \\
Mothers age & 1 & 1.0 to 1.0 \\
Ethnicity & 0.99 & 0.9 to 1.0 \\
Parity & 0.99 & 0.9 to 1.0 \\
Inpatient days adjusted for & \\
Overweight & 1.36 & 1.24 to 1.48 \\
Mothers age & 1.01 & 1.0 to 1.0 \\
Ethnicity & 1.01 & 1.0 to 1.0 \\
Parity & 0.9 & 0.9 to 0.9 \\
Outpatient visits adjusted for & \\
Overweight & 1.1 & 1.0 to 1.2 \\
Mothers age & 1 & 1.0 to 1.0 \\
Ethnicity & 0.96 & 0.9 to 1.0 \\
Parity & 1 & 1.0 to 1.1 \\
GP visits adjusted for & & \\
Overweight & 1.07 & 1.01 to 1.14 \\
Mothers age & 1 & 1.0 to 1.0 \\
Ethnicity & 0.98 & 0.9 to 1.0 \\
Parity & 0.97 & 0.9 to 1.0 \\
Medication adjusted for & 1.14 & 1.1 to 1.2 \\
Overweight & 1 & 1.0 to 1.0 \\
Mothers age & 0.98 & 1.1 to 1.1 \\
Ethnicity & 1.1 & \\
Parity & BMI, body mass index;GP, general practitioner, RR, rate ratio.
\end{tabular}

Table 6 shows the mean total cost for each BMI category calculated using (1) inpatient costs (2) outpatient costs (3) cost of GP visits and (4) cost of medications prescribed by the GP. As shown obese women cost a mean total of $£ 1172(p=0.01)$ more than the normal weight group. Overweight women also had a higher mean total cost in comparison with normal weight women, however this finding was not statistically significant.

\section{DISCUSSION}

Various studies have reported the increasing number of adverse outcomes among obese women during pregnancy, ${ }^{2-5}$ but few have quantified the healthcare costs

Table 4 Relative rates of total health service costs with BMI (£s/11 months)

\begin{tabular}{lll}
\hline Health service & $\begin{array}{l}\text { Normal BMI* } \\
\text { BMI 18.5-24.9 }\end{array}$ & $\begin{array}{l}\text { Overweight plus } \\
\text { BMl>24.9 }\end{array}$ \\
\hline Inpatient & $2644(144.3)$ & $1.27(1.26$ to 1.27$)$ \\
Outpatient & $345(29)$ & $1.17(1.16$ to 1.18$)$ \\
GP & $692(25.96)$ & $1.10(1.09$ to 1.11$)$ \\
Medication & $9(0.8)$ & $1.16(1.09$ to 1.23$)$ \\
Total costs & $4003(184)$ & $1.20(1.19$ to 1.20$)$ \\
\hline
\end{tabular}

Unless stated data are represented as rate ratios $(95 \% \mathrm{Cl})$.

${ }^{*}$ Reference group for rate ratios, given as mean (SE).

BMI, body mass index;GP, general practitioner. 
Table 5 Total cost for all healthcare usage adjusted for confounders and comorbidities

\begin{tabular}{lll}
$\begin{array}{l}\text { Body mass } \\
\text { index }\end{array}$ & $\begin{array}{l}\text { Model } \mathbf{1} \\
\text { RR }(\mathbf{9 5 \%} \mathbf{C l})\end{array}$ & $\begin{array}{l}\text { Model } \mathbf{2} \\
\mathbf{R R}(\mathbf{9 5 \%} \mathbf{C l})\end{array}$ \\
\hline$<25$ & 1 & 1 \\
$25-29.9$ & $1.23(1.230$ to 1.233$)$ & $1.23(1.22$ to 1.23$)$ \\
$>29.9$ & $1.37(1.37$ to 1.38$)$ & $1.39(1.38$ to 1.39$)$ \\
\hline
\end{tabular}

Model 1: adjusted for age, ethnicity and parity.

Model 2: adjusted for age, ethnicity, parity and comorbidity.

$\mathrm{RR}$, rate ratio.

associated with increasing health service utilisation. Adopting an econometric approach, our findings have shown that women who are overweight or obese at pregnancy booking are more likely to accrue a higher number of health service visits and accompanying healthcare costs throughout the course of pregnancy. An exception was shown among the youngest group of overweight/obese women (aged 18-20 years) who revealed a significantly lower health service cost in comparison with normal BMI counterparts. We found a $23 \%$ and $39 \%$ increase in total health service costs for overweight and obese women, respectively. Among our study population this equated to an extra $£ 698$ for overweight and $£ 1172$ for obese women when compared with costs accrued by women with a normal BMI.

Specifically looking at the type of health services accessed, overweight and obese women had approximately 15-20\% greater healthcare usage of all hospital services, a $30 \%$ higher mean number of days spent in hospital, and a $10 \%$ higher mean usage of GP services. Consequently, the overweight and obese women accrued higher costs through generic use of healthcare services, not through one particular area of health service. Given the variety of methodologies used by previous studies it is difficult to directly compare our findings, however previous studies also highlight increasing health service usage and/or healthcare costs according to increasing maternal BMI. ${ }^{14-16} 2829$ One prospective case-control study reported average prenatal care costs as five times higher for women who were overweight before pregnancy in comparison with normal-weight control women. $^{28}$ Collecting data during pregnancy and the postpartum period, the study also reported that overweight women had a higher duration of day and night hospitalisation by 3.9-fold and 6.2-fold correspondingly. Denison et $a l^{29}$ reported increasing costs from minor complications throughout pregnancy as maternal BMI increased. In this study, retrospectively analysing antenatal notes and labour ward records, costs concerning staff, facilities and consumables were calculated for the NHS. In comparison with normal weight women, overweight and obese women cost on average an extra $£ 33.21$ and $£ 31.02$, respectively, when considering costs associated with minor complications. Higher healthcare costs were attributed to increasing medication usage with obese women requiring treatment for more minor complications.

Maternal overweight and obesity have also been shown to negatively impact on the subsequent health of offspring. Enhanced risk of adverse perinatal outcomes, ${ }^{30}$ delayed mental development ${ }^{31}$ and the development of later obesity $^{32}$ have been reported. One study reported offspring born to women with a BMI greater than 26 were 3.5 times more likely to require admission to a neonatal ward ${ }^{33}$ while another found a $15 \%$ increased risk of offspring being obese at age 4 years among obese mothers. $^{32}$ A report released in 2011 estimated that childhood obesity in London alone cost the NHS £7.1 million (year 2006/2007) for providing GP appointments, inpatient and outpatient care and medications to treat conditions related to childhood obesity. ${ }^{34}$ Furthermore the report estimated future costs at $£ 110.8$ million/year (including direct and indirect costs) if children became obese adults. Consequently, in addition to the healthcare costs estimated within this study, it is important to acknowledge the perpetuating cycle of increasing healthcare costs from an intergenerational effect of maternal obesity.

A strength of this study was the unique opportunity to control for important potential confounders such as age, sociodemographic variables, smoking status, alcohol consumption and comorbidities through data collection at the patient level. This enabled us to exclude one participant with a record of cancer within the 3 years preceding conception. Often studies using self-reported information have shown an underestimation when reporting chronic conditions. ${ }^{35} \mathrm{~A}$ further strength of this study is the use of medically recorded BMI values. As frequent misclassification especially among overweight and obese women has been documented when using self-reported BMI measures, ${ }^{36}$ we have been able to minimise uncertainty associated with recall bias.

Several limitations of our study must be also considered. First, relying on a BMI value recorded at a single time point, and early in pregnancy, may cause methodological issues provided that women can alter weight status throughout pregnancy. ${ }^{12}$ Second, gestational weight gain was not considered, yet women entering

Table 6 Total cost for normal body mass index(BMI), overweight and obese women

\begin{tabular}{llll}
\hline & $\begin{array}{l}\text { Normal BMI } \\
\text { BMI<25 }\end{array}$ & $\begin{array}{l}\text { Overweight } \\
\mathbf{2 4 . 9 < B M I < 3 0}\end{array}$ & $\begin{array}{l}\text { Obese } \\
\mathbf{B M I} \geq \mathbf{3 0}\end{array}$ \\
\hline Total mean cost $(£)$ & 3546 & 4244 & 4718 \\
$95 \% \mathrm{Cl}$ & $(3238.6$ to 3854.0$)$ & $(3647.7$ to 4841.0$)$ & $(4038.5 \text { to } 5396.8)^{*}$ \\
\hline
\end{tabular}


pregnancy with a higher BMI have been shown to gain lower levels of weight compared with those with a lower BMI, and may even lose weight during pregnancy. ${ }^{37-39}$ Third, our study specifically adopted a prevalence-based approach for examining health service utilisation over an 11-month period. Our reported cost estimates are therefore likely to be conservative as they do not account for those costs that are indirect (eg, costs due to absenteeism, travel costs, household production and informal healthcare costs) or intangible (eg, costs of suffering to the individual). Furthermore, in addition to these excluded costs, our findings do not consider backloaded costs which are likely to occur from subsequent pregnancies, given that obese women are more likely to be heavier in subsequent pregnancies ${ }^{40}$ and that associated comorbidities develop after the onset of obesity. ${ }^{41}$ It is important to note that there is no standard costing system used throughout the UK NHS and as such the unit costs applied as part of this study merely reflect an average of the resource costs borne in Wales over a certain period. This creates great difficulty when trying to deduce actual resource utilisation at an individual hospital episode level, and means that the unit costs used here may differ from those reported elsewhere in the UK NHS. Nonetheless, the unit costs from the WCR accounts used throughout this study are validated annually during the completion of the Welsh Benchmarking Summary (WBS), providing a robust costing methodology.

Fourth, relying on electronic health records presents difficulties when trying to quantify the type of event occurring and the appropriate cost to be assigned. In some cases an individual would have more than one health event record occurring on the same day within the GP data. Methods currently used for recording data make it impossible to differentiate between an actual GP consultation and an administration process (eg, a letter sent to a consultant or a patient telephone call). It was therefore decided to utilise only one event per recorded date and to assume that it was a GP consultation (after excluding medication Read codes). Similarly, the outpatient data also revealed numerous events occurring on the same date which could signify the movement of a patient across specialties. We opted to apply the specialty cost equating to the first event code only. It is also important to note that we could only ascertain medication usage from GP datasets, therefore this estimate is undervalued without the use of hospital data. Finally, given the nature of our study population it was likely that study participants received healthcare from a community mid-wife. Unfortunately this contact was not included within the scope of this study, as data were not available on community practices within the electronic records. Again, our findings are therefore likely to provide a conservative cost estimate.

Despite these limitations, our study findings provide strong evidence for an increase in health service utilisation and accompanying direct healthcare costs in women presenting with a BMI higher than normal during pregnancy. Looking at the number of births in the UK in 2012 (812 920) and applying the findings from this study, an additional £144818 105 would have been spent on healthcare services for obese women during a 11-month period. This amount of capital could become cost-effective if utilised to fund public health interventions targeting maternal lifestyle and subsequently reduce the healthcare usage of obese women. Future planned work within the cohort population described shall investigate the reasons why overweight and obese women accrue higher rates of health service use and accompanying costs, with specific focus on the specialties accessed and timing of usage.

\section{Author affiliations}

${ }^{1}$ College of Medicine, Swansea University, Swansea, UK

${ }^{2}$ Institute of Life Sciences, Swansea University, Swansea, UK

${ }^{3}$ School of Medicine, Cardiff University, Cardiff, UK

${ }^{4}$ Keele Management School, Keele University, Keele, UK

Acknowledgements The work was supported by NISCHR and Swansea University. This study makes use of anonymised data held in the Secure Anonymised Information Linkage (SAIL) system, which is part of the national e-health records research infrastructure for Wales. The authors would like to acknowledge all the data providers who make anonymised data available for research. This work is also part of the 'Growing Up in Wales: EHL' study.

Contributors KLM and STB conceived and designed the study. KLM was the guarantor of this article and responsible for the statistical analysis and writing process under the guidance of STB, MJH and SP. MAR along with MDA was responsible for all data extraction from the Secure Anonymised Information database. KLM, RAH and AK were responsible for data collection methods. All authors reviewed the final manuscript.

Funding Swansea University and NISCHR.

Competing interests None.

Ethics approval South East Wales Research Ethics Committee for Wales.

Provenance and peer review Not commissioned; externally peer reviewed.

Data sharing statement Data are stored within the Secure Anonymised Information Linkage (SAIL) databank at the Health Information Research Unit (HIRU) at Swansea University. All proposals to use SAIL datasets must comply with HIRU's information governance policy.

Open Access This is an Open Access article distributed in accordance with the Creative Commons Attribution Non Commercial (CC BY-NC 3.0) license, which permits others to distribute, remix, adapt, build upon this work noncommercially, and license their derivative works on different terms, provided the original work is properly cited and the use is non-commercial. See: http:// creativecommons.org/licenses/by-nc/3.0/

\section{REFERENCES}

1. Centre for Maternal and Child Enquiries. Maternal obesity in the UK: findings from a national project. London: CMACE, 2010.

2. Arrowsmith S, Wray S, Quenby S. Maternal obesity and labour complications following induction of labour in prolonged pregnancy. BJOG 2011;118:578-88.

3. Green C, Shaker D. Impact of morbid obesity on the mode of delivery and obstetric outcome in nulliparous singleton pregnancy and the implications for rural maternity services. Aust N Z J Obstet Gynaecol 2011;51:172-4.

4. Cedergren MI. Non-elective caesarean delivery due to ineffective uterine contractility or due to obstructed labour in relation to maternal body mass index. Eur J Obstet Gynecol Reprod Biol 2009;145:163-6.

5. Sherrard A, Platt RW, Vallerand D, et al. Maternal anthropometric risk factors for caesarean delivery before or after onset of labour. BJOG 2007;114:1088-96. 
6. Hilder L, Costeloe K, Thilaganathan B. Prolonged pregnancy: evaluating gestation-specific risks of fetal and infant mortality. BJOG 1998;105:169-73.

7. Denison FC, Price J, Graham C, et al. Maternal obesity, length of gestation, risk of postdates pregnancy and spontaneous onset of labour at term. BJOG 2008;115:720-5.

8. Heslehurst N, Lang R, Rankin J, et al. Obesity in pregnancy: a study of the impact of maternal obesity on NHS maternity services. BJOG 2007; 114:334-42.

9. Larg A, Moss JR. Cost-of-illness studies: a guide to critical evaluation. Pharmacoeconomics 2011;29:653-71.

10. Raebel MA, Malone DC, Conner DA, et al. Health services use and health care costs of obese and nonobese individuals. Arch Intern Med 2004;164:2135-40.

11. Quesenberry CP Jr, Caan B, Jacobson A. Obesity, health services use, and health care costs among members of a health maintenance organization. Arch Intern Med 1998;158:466-72.

12. Withrow D, Alter DA. The economic burden of obesity worldwide: a systematic review of the direct costs of obesity. Obes Rev 2011;12:131-41.

13. Vellinga A, O'Donovan D, De La Harpe D. Length of stay and associated costs of obesity related hospital admissions in Ireland. BMC Health Serv Res 2008;8:88.

14. Stringer M, Ratcliffe SJ, Evans EC, et al. The cost of prenatal care attendance and pregnancy outcomes in low-income working women. J Obstet Gynecol Neonatal Nurs 2005;34:551-60.

15. Harrison MJ, Kushner KE, Benzies K, et al. In-home nursing care for women with high-risk pregnancies: outcomes and cost. Obstet Gynecol 2001;97:982-7.

16. Elixhauser A, Wier LM. Complicating Conditions of Pregnancy and Childbirth, 2008. HCUP Statistical Brief \#113. May 2011. Agency for Healthcare Research and Quality, Rockville, MD. http://www.hcupus.ahrq.gov/reports/statbriefs/sb113.pdf

17. Kolu P, Raitanen J, Rissanen P, et al. Health care costs associated with gestational diabetes mellitus among high-risk women-results from a randomised trial. BMC Pregnancy Childbirth 2012;12:71.

18. BBC News W. Wales faces deepest NHS cuts in UK says King's Fund. 2011.

19. Welsh Government. A Strategic Vision for Maternity Services in Wales: Crown copyright 2011:1-31.

20. Hill R, Brophy S, Brunt $\mathrm{H}$, et al. Protocol of the baseline assessment for the Environments for Healthy Living (EHL) Wales cohort study. BMC Public Health 2010;10:150.

21. Ford D, Jones K, Verplancke J-P, et al. The SAIL Databank: building a national architecture for e-health research and evaluation. BMC Health Serv Res 2009;9:157.

22. Brooks CJ, Stephens JW, Price DE, et al. Use of a patient linked data warehouse to facilitate diabetes trial recruitment from primary care. Prim Care Diabetes 2009;3:245-8.

23. Welsh Government. Financial Information Strategy Programme. Consolidated Local Health Boards WCR1 Costing Returns. Wales, 2012.
24. Personal Social Services Research Unit. Unit costs of health and social care 2011. In: Curtis L. ed, 2011:1-230.

25. British Medical Association and the Royal Pharmaceutical Society of Great Britain, ed. British national formulary. London: BMJ Group and Pharmaceutical Press, 2013.

26. Charlson ME, Pompei $\mathrm{P}$, Ales $\mathrm{KL}$, et al. A new method of classifying prognostic comorbidity in longitudinal studies: development and validation. J Chronic Dis 1987;40:373-83.

27. Khan NF, Perera R, Harper S, et al. Adaptation and validation of the Charlson Index for Read/OXMIS coded databases. BMC Fam Pract 2010;11:1.

28. Galtier-Dereure F, Boegner C, Bringer J. Obesity and pregnancy: complications and cost. Am J Clin Nutr 2000;71:1242S-8S

29. Denison FC, Norrie G, Graham B, et al. Increased maternal BMl is associated with an increased risk of minor complications during pregnancy with consequent cost implications. BJOG 2009;116:1467-72.

30. Athukorala $\mathrm{C}$, Rumbold $\mathrm{AR}$, Willson $\mathrm{KJ}$, et al. The risk of adverse pregnancy outcomes in women who are overweight or obese. BMC Pregnancy Childbirth 2010;10:56.

31. Hinkle SN, Schieve LA, Stein AD, et al. Associations between maternal prepregnancy body mass index and child neurodevelopment at 2 years of age. Int J Obes 2012;36:1312-19.

32. Whitaker RC. Predicting preschooler obesity at birth: the role of maternal obesity in early pregnancy. Pediatrics 2004;114:e29-36.

33. Galtier-Dereure F, Montpeyroux F, Boulot P, et al. Weight excess before pregnancy: complications and cost. Int $J$ Obes Relat Metab Disord 1995;19:443-8.

34. Health and Public Services Committee. Tipping the scales childhood obesity in London. London: Greater London authority, 2011.

35. Harlow SD, Linet MS. Agreement between questionnaire data and medical records. The evidence for accuracy of recall. $A m \mathrm{~J}$ Epidemiol 1989;129:233-48.

36. Shub A, Huning EY-S, Campbell K, et al. Pregnant women's knowledge of weight, weight gain, complications of obesity and weight management strategies in pregnancy. BMC Res Notes 2013;6:278

37. Nohr EA, Vaeth M, Baker JL, et al. Pregnancy outcomes related to gestational weight gain in women defined by their body mass index, parity, height, and smoking status. Am J Clin Nutr 2009;90: 1288-94.

38. Kiel DWDE, Artal R, Boehmer TK, et al. Gestational weight gain and pregnancy outcomes in obese women: how much is enough? Obstet Gynecol 2007;110:752-8.

39. Bodnar LMS-RA, Simhan HN, Himes KP, et al. Severe obesity, gestational weight gain, and adverse birth outcomes. Am J Clin Nutr 2010;91:1642-8.

40. Villamor E, Cnattingius S. Interpregnancy weight change and risk of adverse pregnancy outcomes: a population-based study. Lancet 2006;368:1164-70.

41. Sturm R. The effects of obesity, smoking, and drinking on medical problems and costs. Health Aff 2002;21:245-53. 